\title{
Presupposed evaluation in environmental argumentative discourse
}

\begin{abstract}
Expressions of evaluation in discourse have been studied from a number of different perspectives, all highlighting the fact that evaluation may be expressed cumulatively, through a combination of different linguistic means, and pragmatically, at various levels of implicitness, which often defy precise categorization.

This paper argues that, in argumentative discourse, the pragmatics of evaluation includes not only implied but also presupposed aspects. A case study centred on the environmental debate over the contested practice of fracking is used to identify the evaluative premises that lie behind the main stances or claims on the issue, as expressed by different stakeholders. It is argued that this wider approach to the analysis of evaluation may be particularly suited to uncover the evaluative premises that lie at the core of different and often contradictory environmental positions and policies.
\end{abstract}

\section{Introduction}

It is widely acknowledged that register and text type play an important role in the identification of evaluative meaning. For example, Benamara et al. (2017: 54) argue that register considerations provide "important clues to recognizing implicit opinions". This link has been highlighted with particular reference to overtly evaluative registers such as tourist websites (Kaltenbacher 2006) or property advertising (Pounds 2011). These studies have focused specifically on how the evaluative function of particular expressive choices is activated in the context of the overall promotional function of the registers they appear in.

The aim of this paper is to explore the pragmatics of evaluation by focusing on how evaluation may be presupposed as well as implied, with specific reference to argumentative registers. Environmental argumentative discourse is chosen for this analysis because stakeholders' positions are particularly polarized in this context. Beyond political and individual self-interest, widely different views on how to address environmental issues arise, partly because different stakeholders subscribe to fundamentally different values, reflecting the particular ideological viewpoints and interests of different social groups.

This paper is particularly concerned with the evaluative presuppositions that underlie these different views. Specifically, I will show how evaluative meaning may not only be directly stated or implied in discourse, as extensively evidenced in previous theories and analysis, but also presupposed. In order to do this, I firstly (section 2) clarify the notion of evaluation in language, specifically the concept of APPRECIATION within Appraisal Theory (Martin and White 2005; White 2006; Macken- 
Horarik \& Isaac 2014). In section 3, I illustrate how this conceptualization may be extended to capture further evaluative dimensions with specific reference to argumentative discourse. The example used for illustration is an article from BBC News in which four stakeholders express their views of the controversial practice of hydraulic fracturing, more commonly known as 'fracking'. ${ }^{1}$ The analysis of the viewpoints presented in this article (section 4) serves the purpose of showing how the main stance taken by each stakeholder may be traced back to underlying evaluative premises. ${ }^{2}$ Whilst the focus of the analysis is primarily on evaluative meaning, basic concepts from argumentation theory (such as claims, premises and warrants) are mobilized to illustrate the presupposed dimension of evaluation. The implications of the findings are further discussed in section 5, with reference, firstly, to evaluative meaning, presupposition and argumentation theory and, secondly, environmental policy deliberations.

\section{Evaluation in discourse}

In its widest understanding, evaluative language (EL) includes the range of linguistic resources that may be used to express language users' attitude or stance (views or feelings) to entities in the real world (e.g. France is a beautiful country; I love my children) or to propositions (e.g. epistemic stance: I'm sure they are right or deontic stance: It is essential that they start now). From a Systemic Functional perspective (Halliday and Matthiessen 2004), EL fulfils primarily an interpersonal function in discourse in that it is typically expressed to engage, shape and influence others' views and feelings. A number of attitudinal parameters have been identified by different researchers, notably AFFECT, JUDGMENT and APPRECIATION (Martin \& White 2005), and EMOTIVITY, RELEVANCE/ IMPORTANCE, RELIABILITY, EXPECTEDNESS, COMPREHENSIBILITY (Bednarek 2006, inter alia). Most of these parameters work on a basic high/low or positive/negative continuum. Further key variables affecting the nature and impact of evaluation are the source of the evaluation (e.g. whether it is authorial or attributed to third parties), the target (e.g. whether entities, people or propositions), the degree of subjectivity versus factuality embedded in the evaluation (e.g. brilliant may be a more subjective evaluation than thin, referring to a person) and levels of explicitness (e.g. I felt embarrassed is a more explicit way of referring to one's feelings than saying $I$ didn't know what to say). While some evaluative meanings may be associated with specific linguistic 
expressions (e.g. modal verbs and adverbs in English) or morphological structures (e.g. prefixes or suffixes in many languages) others, such as positive or negative appreciation of things or events, are typically realized prosodically in discourse through varying combinations of lexico-grammatical operators. As pointed out in much evaluation research (e.g. Huston \& Thompson 1999), the distinction between evaluative and non-evaluative language is often problematic insofar as evaluative meaning is particularly context-dependent. Many expressions may be primarily factual in some contexts (e.g. a red car) and evaluative (positive or negative) in others (e.g. a red nose or red lips). Moreover, the criteria for positive and negative evaluation of specific entities (e.g. places, products, and people) rely, to a large extent, on unstable and varying sociocultural assumptions and expectations.

Among the most recent conceptualizations of EL, two stand out for the strength of their explanatory power, breadth, insight and applicability: Lemke's (1998) study of evaluation and attitudinal meaning, and Martin and White's (2005) Appraisal Theory. Lemke takes a unitary perspective, underlining the pervasiveness of evaluation. His theory emphasizes the fact that attitude and evaluation have not only interpersonal but also referential aspects as we cannot represent reality without, at the same time, evaluating it, more or less explicitly, as desirable, important, surprising, serious and so forth. Appraisal Theory, on the other hand, places more emphasis on the distinction between the evaluative options available in language, specifically, authorial and projected expression of AFFECT (I hate bananas or she hates bananas), JUDGMENT of people (John is the most generous person I have ever met) and APPRECIATION of objects and events (The concert was a disaster). ${ }^{3}$ Like Lemke (1998), Martin and White (2005) acknowledge the evaluative function of representational choices, distinguishing between: "evaluation that has been directly inscribed in discourse through the use of evaluative lexis" and "invoked evaluation", conveyed through the "selection of ideational meaning even in the absence of attitudinal lexis" (Martin \& White 2005: 6162). Invoked or implied evaluation includes formulations in which the speaker's attitude is expressed through specific representations of participants and events. She hugged her husband, for example, may imply that the speaker wishes to attribute AFFECT to the wife (she loved her husband) or/and convey a positive judgment of her (she was a caring person). Martin and White (2005: 63) argue that 
"the inscriptions act as sign-posts...telling us how to read the ideational selections that surround them". Different forms of invocation are distinguished, within the original Appraisal framework, "according to the degree of freedom allowed readers in aligning with the values naturalised by the text" (2005: 67). Using an example of APPRECIATION (evaluation of entities or event), applied to an environmental phenomenon (CO2 emissions), the different forms that evaluation may take within the Appraisal system are shown in Table 1.

Table 1. Showing forms of evaluative expression (APPRECIATION) by level of implication (adapted from Martin and White 2005: 67). The examples have been constructed by the present author.

\section{Levels of implication}

INSCRIBED:

INVOKED:

INVITED:

AFFORDED:

FLAGGED:

PROVOKED:

\author{
Linguistic realisation (example) \\ CO2 emissions are dangerous/ \\ lethal.

CO2 emissions may cause allergies.
CO2 emissions compromise our way
of life.

Our cities are gripped by $\mathrm{CO} 2$ emissions.

\section{Linguistic level}

denoted meaning evaluation through transitivity choices (negative outcome of $\mathrm{CO} 2$ emissions in this case) evaluation through use of noncore, value-laden lexis (compromise in this case) evaluation through suggestive figurative language

White (2006) identifies further forms of provoked evaluation triggered by expressions of counterexpectation and intensification. With reference to the examples in Table 1, these would be expressions such as: $\mathrm{CO} 2$ emissions are still very much detectable in the Western world in which still (counterexpectation) and very much (intensification), individually or in combination, trigger an evaluative interpretation.

Within the options illustrated in Table 1, the inscribed formulations (i.e. formulations that are recognizable as clear expression of the speaker's attitude) are at one extreme end of the explicitness continuum whilst the afforded type (i.e. formulations whose evaluative role is least directly detectable) may be placed towards the other end of the continuum. 
White (2006: 45) identifies a further invoked type, "evocation via informational content", which may be placed even closer to the end of the continuum. This type includes formulations in which speakers introduce factual content, which, in a particular context, may be interpreted as evaluative. White's example quoted from a news report in The Times (9-1-1999) is: "They [police officers] opened fire after being shot at themselves" in which the subordinate clause is factual in itself but may trigger a more positive evaluation of the police action (as reacting to rather than instigating the violence) than would otherwise be the case. A further related consideration is that the phrase $\mathrm{CO} 2$ emissions itself may also be seen as one such factual expression to the extent that it evokes a strong negative evaluative meaning because of the negative connotation it has acquired due to its uses in previous contexts (the negative meaning is, in other words, pragmatic rather than semantic).

Macken-Horarik \& Isaac (2014: 76) further identify more implicit reader-dependent evaluation-affording options, in which ideational meanings refer to defining culturally-shared texts and events, as in examples (1) and (2).

(1) Modern Bible writers would include CO2 emissions in their descriptions of the Last Judgement.

(2) CO2 emissions do not have a place in human progress. ${ }^{4}$

In example (1), the negative evaluation of $\mathrm{CO} 2$ emissions relies on the speakers' shared knowledge of the Bible and its portrayal of the Last Judgment as a catastrophic event whilst, in example (2), it relies on the widely shared assumption that human progress is a positive development.

An overview of the Appraisal evaluative options, integrating Martin \& White (2005), White (2006) and Macken-Horarik \& Isaac (2014), by the degree to which they rely on reader inference and context is provided in Table 2 .

Although this extended framework accounts for further levels of implicitness than the original Appraisal system, the focus remains on the cumulative and associative build-up of evaluative meanings in texts. This may be described as a bottom-up approach focusing on co-occurrence. The direction of evaluative meaning retrieval is inferential, that is from local formulations to global stance. This prevalent conceptualization of discourse evaluation is represented in Box 1. 
Table 2. Degrees of evaluative explicitness, integrating Martin and White (2005), White (2006) and Macken-Horarik \& Isaac (2014)

Levels of explicitness

Examples

\begin{tabular}{|c|c|c|}
\hline \multirow{6}{*}{$\begin{array}{l}\text { Most explicit and least } \\
\text { context/reader-dependent }\end{array}$} & Inscribed & $\begin{array}{l}\text { CO2 emissions are dangerous/ lethal } \\
\text { (denotation) }\end{array}$ \\
\hline & $\begin{array}{l}\text { Invoked } \rightarrow \text { invited } \rightarrow \text { flagged (or attitudinal } \\
\text { association in White 2006) }\end{array}$ & $\begin{array}{l}\text { CO2 emissions compromise our way of } \\
\text { life (value-laden lexis) }\end{array}$ \\
\hline & Invoked $\rightarrow$ provoked & $\begin{array}{l}\text { Our cities are gripped by } \mathrm{CO} 2 \text { emissions } \\
\text { (figurative language) } \\
\text { CO2 emissions are still very much } \\
\text { detectable in the Western world } \\
\text { (counter-expectation and intensification) }\end{array}$ \\
\hline & Invoked $\rightarrow$ invited $\rightarrow$ afforded & $\begin{array}{l}\text { CO2 emissions may cause allergies } \\
\text { (ideational choices) }\end{array}$ \\
\hline & Invoked $\rightarrow$ evoked via informational content & $\begin{array}{l}\text {...after being shot at themselves } \\
\text { (informational content) } \\
\text { CO2 emissions (connotation) }\end{array}$ \\
\hline & Invoked $\rightarrow$ shared cultural events or values & $\begin{array}{l}\text { Modern Bible writers would include } \\
\text { CO2 emissions in their descriptions of } \\
\text { the Last Judgement. } \\
\text { CO2 emissions do not have a place in } \\
\text { human progress }\end{array}$ \\
\hline
\end{tabular}

Box 1. Traditional bottom-up view of evaluation

Overall evaluative stance<smiles>[CH]=C</smiles>

Trigger 1 (inscribed) + Triggers 2, 3, 4... (invoked)

\section{Evaluation, register and argumentation}

As evidenced in the most implicit forms of evaluation reviewed above, register and text type play an important role in the identification of evaluative meaning. This is emphasized, with reference to Appraisal analysis, by Hood \& Martin (2007: 745) who argue that "[T]exts naturalize a reading position which forms the basis for interpreting evaluation, not just for non-evaluative lexis but for 
evaluative lexis as well". Registers may be defined according to their overall functional role or communicative intention. Typical functional roles include narrative, instructional, expository and argumentative functions.

Among the early studies of the relationship between evaluation and register is Labov \& Waletzky's (1967) exploration of how evaluative features shape narrative structure. They observed that evaluative elements appear to cluster at particular points in the narrative, specifically at the beginning and at the end, to express what the narrator perceives to be the point of the narrative, for example, why it is funny, scary or surprising.

Since the early development of Appraisal analysis (culminating with Martin and White's 2005 publication: The language of evaluation. Appraisal in English), many studies have explored how evaluation builds up in overtly evaluative registers such as news media texts (Bednarek 2008), tourist websites (Kaltenbacher 2006) property advertising (Pounds 2011) and wine reviews (Hommerberg \& Don 2015). Although the evaluative resources in these texts have been studied with reference to the registers they belong to, the analytical direction tends to be bottom-up, i.e. from the local evaluative trigger to the wider evaluative interpretation, as illustrated at the end of section 2 .

In the book Evaluation in context edited by Thompson \& Alba-Juez (2014), a number of scholars draw attention to the discursive context that shapes the final evaluative meaning in a variety of different registers. Macken-Horarik \& Isaac (2014: 81), in particular, notice the difficulty in balancing a focus on localised evaluative choices (which often prevents wider and more consonant interpretations) and a more global or synoptic focus (which may lack explanatory power). Their proposal is to proceed recursively, starting from the most explicit evaluative choices in the text (at the top of the cline visualised in Table 2) and then reviewing their meanings in the wider context of, and in combination with, the more implicit references to shared cultural values (at the bottom of the cline in Table 2). Similarly, Thompson (2014: 63-64), building on Hunston (2000: 205), highlights the distinction between two different evaluative and analytical levels, the local Topic-Oriented Appraisal and the global Interaction-Oriented Appraisal. At the local level, the focus is on the individual evaluative choices inside the text. At the global level, the focus is on the relationship between the writer/speaker and reader/listener and how it is shaped by the specific textual function (e.g. narrative 
or argumentative). Thompson hints at the possibility of moving from one level to the other in either direction but stops short of illustrating how this might be achieved.

A bottom-up approach (from the local to the global) has mostly been taken in studies that have specifically investigated the relationship between evaluation and argumentation. Most of these studies (noticeably, Hunston 1989; Hyland 2002; Wu \& Allison 2005) have considered evaluation in argumentative registers of an academic nature, particularly highlighting the function and place of inscribed forms of evaluation, such as modals and evidentials.

An interesting example is Hommerberg's (2015) analysis, in which she explores Appraisal dimensions of evaluation in an atypical form of argumentation: informed and influential wine reviews. She argues that such reviews may be considered argumentative to the extent that the reviewers' varied opinions of the wine may compete with the wine producers and sellers' invariably positive ones. In this study, she uses argumentation theory to explore the difference and relationship between backgrounded assumed evaluation and more explicitly foregrounded evaluation. This is illustrated in the following quote from her corpus of reviews by the US celebrity wine reviewer Robert Parker:

The home estate of the brilliant, world-renowned oenologist Michel Rolland and his equally talented wife Dany Rolland, Bon Pasteur's 2003 [the wine in question] has turned out extremely well... (Hommerberg 2015: 163)

She points out that 'the proposition concerning the wine makers' capacity is presented as unproblematic for the audience, while the evaluation of the wine as having turned out extremely well is presented as new and central information that is up for debate, and possibly as a potentially contentious assessment that requires justification" (Hommerberg 2015: 163). She argues that, in order for the readers to infer the positive assessment of the wine, they have to recover a warrant such as "any wine made by the Rollands is likely to be of high quality". This link is not made explicitly in the text. To this extent, therefore, the evaluation relies on assumed text-external understanding. Although this analysis draws attention to the assumed text-external dimension of evaluation, it does not systematically explore the levels at which these assumptions operate throughout the reviews.

In traditional argumentation research, evaluative considerations typically concern the validity of the assumptions (or premises) on which claims are made. Toulmin et al. (1979) recognised early on 
that the premises are embedded in common sense cultural values and shared views of right and wrong that are not explicitly stated. Since then, argumentation scholars have taken different positions as to the normative ${ }^{5}$ (or evaluative) basis of premises and claims, in terms of their generalisability or objectivity. Whilst pragma-dialecticians (particularly van Eemeren \& Grootendorst 2003) subscribe to the view that validity is related to specific logical/critical reasoning 'rules' that either apply or do not, other argumentation scholars (for example, Johnson \& Blair 2006; Toulmin 2003) argue that validity may be defined by more subjective, reader and context-dependent, evaluative standards. ${ }^{6}$

This paper does not take an a-priori position on this debate but sets out to explore the pragmatics of evaluation within an argumentative structure, focusing on the nature, rather than the validity, of particular assumptions or premises. This involves taking an alternative top-down approach to examining text- or register-specific dimensions of evaluation, which is predicated on the integration of the basic core structure of argumentative discourse with Appraisal-based evaluative parameters.

At its core, argumentative discourse is constituted by one or more conclusions or claims and by a set of grounds (Toulmin et al. 1979) or premises (Walton 2009) that provide the evidence or the reasons for or against the claim. In much argumentative discourse (e.g. newspaper editorials or speeches), the main claims are of an epistemic or/and deontic nature insofar as the writer or speaker frequently takes position in respect to the truth validity of a particular proposition or desirability of a particular course of action, respectively (Pounds 2005). It is, however, very common for writers/speakers' stance to include other attitudinal dimensions. In relatively straight-forward arguments, consisting of positions for or against a particular practice, activity or entity, the conclusion/s or claims may be equated with an overall authorial evaluative stance of APPRECIATION. This APPRECIATION amounts to a global reading position, which may be inferred holistically by the reader, based on specific, more or less explicit, local evaluative choices. ${ }^{7}$

In this paper, I use the terms 'presupposed' and 'assumed' interchangeably, taking a wide pragmatic definition of presupposition/assumption as including the contextual knowledge and values that speakers or readers must share with the discourse producers in order for meanings to be communicated as originally intended by the discourse producers. 
Differently from the typical analytical approach represented at the end of section 2 (Table 2), the analysis presented in this paper does not focus on how local evaluative choices (whether inscribed or invoked) build up to particular evaluative stances. Instead, it takes the lead from argumentative structure and explores how the main stance, or claim, inferred from the text, is grounded in layers of assumed evaluations, cued by non-evaluative expressions or not cued at all. In other words, the focus is on the top-down layering of assumed evaluations, focusing on the progressively deeper embedding of the evaluative premises. This is represented in Box 2.

Box 2. Top-down view of evaluation taken in this analysis

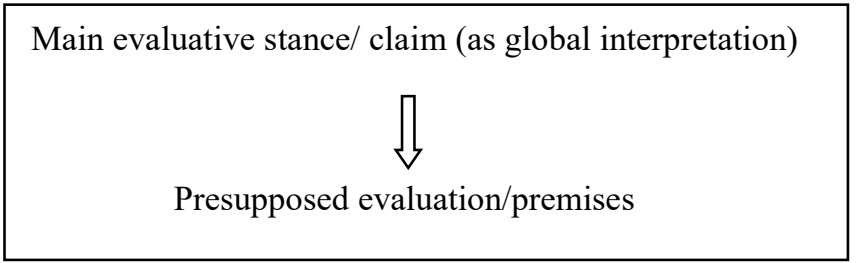

This approach is illustrated in section 4, with specific reference to arguments in favour of and against fracking and is further discussed in in section 5.1 with reference to the theoretical contribution of this study.

\section{Evaluation in environmental argumentation: A case study}

This section presents the analysis of four different viewpoints on the issue of fracking, which are included in an article titled "Viewpoints: Fracking's risks and benefits" published by BBC News online in January 2013. The analysis is divided into two parts. In the first part (section 4.1), the analytical approach is applied to the analysis of the evaluation expressed in each viewpoint. In the second part (section 4.2), the most significant findings are drawn together, providing a clearer overview.

\subsection{Analysis of viewpoints}


In the $\mathrm{BBC}$ article, the included viewpoints are introduced as follows:

Fracking was halted in 2011 after some minor earthquakes near Blackpool, in northwest England, were attributed to test wells being drilled

The UK government recently lifted its moratorium on the controversial process known as hydraulic fracturing, or fracking. The technique involves pumping fluids into a well to recover natural gas from shale rock.

However, fracking has been linked to some minor earthquakes, and there are concerns about its possible environmental impact. So what benefits could hydraulic fracturing bring, and how concerned should we be?

The aim of the news article, as clarified in the title and introduction, is to present the benefits and concerns around the practice of fracking and the opinions represented are chosen precisely because they are very different. The fact that fracking involves both advantages and risks is assumed in the introductory section through the question: "So what benefits could hydraulic fracturing bring, and how concerned should we be?". The intention is to emphasize differences rather than consensus in a seemingly neutral reporting, as typical in quality news coverage, such as that provided by the BBC. ${ }^{8}$ Although it would be possible to analyse the overall evaluative stance taken by the editorial voice in framing the quoted viewpoints in this way, ${ }^{9}$ the analysis presented in this paper focuses on the separate viewpoints as examples of self-contained argumentative pieces. The viewpoints are expressed as responses, by four key stakeholders, to the UK government's lifting of the moratorium on fracking. The stakeholders include: The Director of the Durham Energy Institute, leading research into different energy disciplines; a spokesperson for Shale Gas Europe, an industry-backed resource centre for shale gas information; a campaigner for Friends of the Earth, a global network of environmental organisations; and the Deputy Director of the Tyndall Centre for Climate Change Research, based at Norwich Research Park.

Different stances in environmental argumentative discourse, typically, take the form of negative or positive evaluation of environmental measures (e.g. introducing wind farming, reducing the use of plastic materials) and/or of socio-political or technological initiatives that may have an effect on the environment (e.g. building a new road or fracking, in this case). 
In Appraisal terms (Martin \& White 2005: 56-57), this amounts to negative or positive APPRECIATION (evaluation applied to an entity, activity or practice, rather than a person). ${ }^{10}$ APPRECIATION may be expressed with reference to emotive REACTION (fracking is shocking/exciting), aesthetic REACTION (fracking is ugly/welcome), aesthetic COMPOSITION (fracking is non-sensical/logical) or social VALUATION (fracking is expensive/cheap). Social VALUATION may be seen as the socio-cultural values or "ideational worth" ascribed to entities, phenomena and practices.

For each viewpoint, it is possible to identify the main stance or claim as either positive, negative or mixed. This stance may be partly inscribed and partly invoked. The analysis then identifies three levels of presupposed material that underlie the claims: At the deepest level are the aspects of fracking that are brought to bear on the overall positive or negative evaluation (e.g. environmental risk or economic benefit). References to these criteria are underlined in the texts and summarised in the first columns in Tables 3-6.

Further up we can identify assumptions as to whether these aspects are positive or negative. These assumptions may be placed on a continuum between uncontroversial or disputable. At the one end of the continuum are assumptions that would be shared unproblematically by the majority of readers, such as the assumption that natural disasters are bad and that reducing the probability of natural disasters occurring is good. At the other end of the continuum are assumptions that may be questioned by readers such as the value of meeting gas demand (given the polluting potential of this fuel) and meeting climate targets (which, some readers may see as arbitrary or unrealistic). In my analysis, I have allocated these assumptions to one or the other category, depending on their closeness to either end of the continuum. The category is indicated in the second columns in Tables 3-6.

Further up still are statements or assumptions as to whether these aspects apply or not according to the view holder and this is indicated in the third columns in Tables 3-6. The overall evaluation of fracking is indicated in shaded columns on the right in the summary Tables 3-6. The various steps are explained in further detail for each viewpoint below.

Viewpoint 1 
Prof Richard Davies, Director Durham Energy Institute (leading research into different energy disciplines)

1 During the recent debate on fracking technology in the UK, we may have been distracted from considering

2 some of the real issues in developing our shale gas reserves.

3 The much-popularised link between fracking and contamination of water supplies remains unproven and 4 our research at Durham University shows the chances of it ever happening can be dramatically reduced if

5 the fracking is carried out at vertical distances greater than $600 \mathrm{~m}$ below the drinking water aquifer.

6 We also find that fracking has only caused three reported examples of felt earthquakes (one of which was

7 in Lancashire), but there have been hundreds of thousands of fracking operations.

8 A real issue is that for the UK to produce enough gas for it to make a difference to our indigenous supplies

9 requires a lot of wells - many more than are typical for conventional gas reservoirs.

10 Therefore, the long-term integrity of boreholes and the cement used to seal the boreholes and prevent leaks

11 will be of critical importance.

12 The risks appear to be tiny - of thousands of shale gas wells drilled in the USA, only a handful have 13 reported problems with leakage and all were successfully sealed by subsequent work. But one leaking well 14 is one too many.

15 The UK does not have an abundance of rigs and fracking equipment, so a rapid growth in shale gas 16 production is unlikely.

17 If the social acceptance is there so that enough wells can be drilled, then the long-term integrity of the 18 boreholes is a real issue that will need to be a priority for shale gas companies and regulators.

Prof R.D.'s viewpoint does not include any explicit claims that fracking is either positive or negative. However, a positive view is implied (afforded) throughout in that he undermines the evidence for the potential negative aspects of fracking, particularly in: "the much-popularised link between fracking and contamination of water supplies remains unproven" (L3), "fracking has only caused three reported examples of felt earthquakes" (L6) and "the risks appear to be tiny" (L12). Therefore, his overall position seems to be that fracking is fine overall, provided some precautions are taken.

On a closer analysis, we can see that the aspects of fracking that form the basis of his evaluation are: developing shale gas reserves (L2 and L8) and the overall environmental integrity/safety afforded by the supporting technology (the wells, boreholes and cement L10 and L17- 
18) with particular reference to preventing contamination of water supply (L3) and earthquakes (L6). Each of these aspects is then assumed to be either desirable or not: developing shale gas reserves is assumed to be desirable and so is the environmental integrity/safety. Whilst the former assumption is questionable (Do we need more gas fuel?) the latter is of the uncontroversial kind. These assumptions constitute the evaluative premises for the main claim. Once these criteria are set up in the text, Prof R.D. can then tell us whether they apply or not, thereby fully articulating the evaluative premises on which his claim is founded: He implies that fracking would indeed help develop our shale gas reserves (L2), even though this may require too many wells (L8). Although he repeatedly notices that problems with the supporting technology may compromise environmental integrity (L10; L 12-14 and L17-18), he appears to soften this possibility by stating that these potential problems (contamination of water supplies and earthquakes) are unproven or rare (L3 and L6) and that rapid growth in the fracking industry is not likely to happen (L15). This last statement seems to contradict the initial confidence about shale gas production but boosts his overall cautiously positive stance. The claimpremises analysis is summarized in Table 3.

Table 3. Summary of Viewpoint 1 (Prof Richard Davies Durham Energy Institute)

\begin{tabular}{|c|c|c|c|}
\hline $\begin{array}{l}\text { EVALUATIVE } \\
\text { CRITERIA }\end{array}$ & $\begin{array}{l}\text { EVALUATION of } \\
\text { CRITERIA } \\
\text { (desirability) }\end{array}$ & Does it apply? & $\begin{array}{l}\text { CLAIM/OVERALL } \\
\text { APPRECIATION of } \\
\text { TARGET (FRACKING) }\end{array}$ \\
\hline Meeting gas demand & Yes (disputable) & Yes & \\
\hline $\begin{array}{l}\text { Environmental } \\
\text { integrity/safety (water } \\
\text { contamination and } \\
\text { earthquakes) }\end{array}$ & No (uncontroversial) & Unlikely & $\longleftarrow$ Cautiously POS \\
\hline
\end{tabular}

This analysis allows us to see that the underlying evaluative basis for the APPRECIATION is social VALUATION centred on gas production and environmental integrity/safety.

Viewpoint 2

Mónica Cristina, spokesperson, Shale Gas Europe (an industry-backed resource centre for shale gas information) 
1 Shale Gas Europe welcomes the UK Government's decision to lift its temporary ban on exploratory

2 hydraulic fracturing for shale gas in the UK.

3 The lifting of the ban now allows the UK to explore the potential of securing its energy supply, to stimulate

4 jobs and the economy alongside reducing $\mathrm{CO} 2$ emissions when replacing higher-carbon-content fuels.

5 In addition to this, [Energy Secretary] Ed Davey has made the case that shale gas could prove particularly

$6 \quad$ valuable in replacing the UK's dwindling North Sea supplies.

7 The potential opportunity is substantial. As the British Geological Survey estimates, UK shale gas 8 resources may be 50\% larger than conventional gas resources. With exploratory drilling now going ahead, 9 estimates will be more accurate and the British Geological Survey is due to release a more comprehensive 10 estimate of the UK's shale gas resources in 2013.

11 The UK Government's approach is also environmentally responsible. The UK has conducted a thorough 12 review of hydraulic fracturing and there is substantial scientific evidence to support the UK Government's 13 decision. In June 2012, the Royal Society and the Royal Academy of Engineering concluded that the 14 health, safety and environmental risks associated with the technique can be effectively managed.

15 The government decision to move forward with the safe and sustainable development of its domestic 16 natural gas resources is an economic opportunity which should be embraced.

As in Viewpoint 1, Viewpoint 2 does not include any explicit evaluation that fracking is good or bad but a positive stance is strongly implied by the relatively explicit positive evaluation of the government's decision to lift the ban on fracking. The positive APPRECIATION of the ban is afforded through ideational choices referring to SGE "welcoming" the ban (L1), the positive consequences of lifting the ban (L3-4) and the qualification of the ban as "environmentally responsible" (L11 and 13-14) and as an "economic opportunity" (L16). The fact that the practice is referred to with the more neutral term "exploratory hydraulic fracturing" (L1-2) rather than the negatively connoted 'fracking' is also consistent with positive evaluation.

The analysis can now turn to the evaluative premises on which this positive stance appears to be based. The premises include: meeting gas demand (L2, 3, 6 and 7-8), economic prosperity, job creation and reducing CO2 emissions (L3-4 and 16). As in Viewpoint 1, meeting gas demand is, controversially, assumed to be desirable and to apply as a consequence of the ban lifting. Economic prosperity, job creation and reducing CO2 emissions are also, uncontroversially, assumed to be desirable and presented as applicable. Other than reduction in $\mathrm{CO} 2$, further environmental as well as health and safety risks are mentioned at the end (L11 and 14). They are, uncontroversially, assumed to 
be undesirable but are presented as non-applicable, thus further reinforcing the overall positive APPRECIATION of fracking. The claim-premises analysis is summarised in Table 4.

Table 4. Summary of Viewpoint 2 (Shale Gas Europe)

\begin{tabular}{|l|l|l|l|}
\hline $\begin{array}{l}\text { EVALUATIVE } \\
\text { CRITERIA }\end{array}$ & $\begin{array}{l}\text { EVALUATION of } \\
\text { CRITERIA } \\
\text { (desirability) }\end{array}$ & Does it apply? & $\begin{array}{l}\text { CLAIM/OVERALL } \\
\text { APPRECIATION of TARGET } \\
\text { (FRACKING) }\end{array}$ \\
\hline Meeting gas demand & Yes (disputable) & Yes & \multirow{3}{*}{} \\
\hline Jobs, economic benefit & Yes (uncontroversial) & Yes & \\
\cline { 1 - 3 } Reducing CO2 emissions & Yes (uncontroversial) & Yes & \\
\cline { 1 - 2 } Environmental risk & No (uncontroversial) & No & \\
\cline { 1 - 2 } Health risk & No (uncontroversial) & No & \\
\cline { 1 - 2 } Safety risk & No (uncontroversial) & No & \\
\hline
\end{tabular}

All in all, the assumed fundamental evaluative premise for Viewpoint 2 is, once more, social VALUATION, specifically gas production, environmental integrity and safety (as in Viewpoint 1) but also economic benefit. Meeting gas demand is emphasised more than in Viewpoint 1 and this is not surprising, given the identity of the opinion holder.

\section{Viewpoint 3}

Helen Rimmer, Friends of the Earth (Campaigner for Friends of the Earth, a global network of environmental organisations)

1 The Government's decision to give fracking the green light will send shock waves through communities

2 across the country.

3 And they are right to be alarmed. Fracking is banned in France and Bulgaria, with moratoriums in place in 4 large parts of Europe. A recent EU report warned that fracking poses high risks of water contamination and 5 air pollution - and there have been instances of both in the United States.

6 Fracking also uses huge quantities of water - around four million gallons for each [borehole]. This could 7 have major repercussions for precious supplies. The south-east of England, an area the fracking industry is 8 particularly interested in, already has water supply problems and was in drought earlier this year.

9 The local economy could also be hit. Experience from the US and Australia shows key sectors such as 10 agriculture and tourism have suffered and that local house prices could fall. Furthermore, the jobs benefits 11 are frequently over-stated.

12 Then there is the crucial climate impact. The Government's official climate advisors warn that the nation's 13 power sector must be largely decarbonised by 2030 if the UK is to meet its climate targets. Fracking is part 14 of the Government's reckless dash for gas that would leave the UK hooked on dirty gas for decades.

15 The cheap fuel argument is simply a mirage. Earlier this week Government advisors said shale gas wasn't a 16 10"game-changer" as it could only meet a relatively small share of gas demand. 
17 The reality is we do not need to gamble on fracking. Investing in clean British energy from the wind,

18 waves and Sun - along with a major energy-saving drive - would create hundreds of thousands of new jobs,

19 boost energy security and keep the lights on.

20 It is time to take our foot off the gas and develop a cleaner, safer energy system we can all afford.

In Viewpoint 3, the main claim/evaluative stance can be seen to be an overall negative APPRECIATION of fracking. The most explicit formulations of this stance include invoked negative APPRECIATION through ideational choices, qualifying fracking as "banned" in other countries (L3) and as "part of the Government's reckless dash for gas" (L14) and referring to its negative effects: "high risk of water contamination and air pollution" (L4-5), using up too much water (L6-8), detrimentally affecting the economy (L9-11) and the climate (L12-14) and not meeting the gas demand (L16). Further negative APPRECIATION is evoked through negative evaluation of the ban lifting, which is achieved through projected expression of AFFECT at the beginning of the text (L12). The AFFECT is the "shock" that "communities across the country" are expected to feel at the news of the lifting, according to Helen Rimmer. As in the previous Viewpoints, further analysis unveils the assumed evaluative criteria that underlie the overall negative stance. These criteria appear to be more numerous than in Viewpoints 1 and 2 and include: meeting climate targets (L13), meeting the demand for clean and safe energy (L 14 and 20) and energy saving (L18). As in Viewpoints 1 and 2, they also include meeting gas demand (L16) and environmental risks, such as water contamination or shortage and air pollution (L4-5 and 6-8), and economic benefit (L9-11). The first three criteria are assumed to be desirable but presented as not applicable. Meeting gas demand and economic benefit are also assumed to be desirable, with the former deemed not applicable and the latter as unlikely to be applicable. Environmental risks are assumed to be undesirable and presented as applicable. As in the previous Viewpoints, a distinction can be made regarding the nature or the assumptions (disputable or uncontroversial). The claim-premises analysis is summarised in Table 5.

Table 5. Summary of Viewpoint 3 (Helen Rimmer - Friends of the Earth)

\begin{tabular}{|l|l|l|l|}
\hline $\begin{array}{l}\text { EVALUATIVE } \\
\text { CRITERIA }\end{array}$ & $\begin{array}{l}\text { EVALUATION of } \\
\text { CRITERIA } \\
\text { (desirability) }\end{array}$ & Does it apply? & $\begin{array}{l}\text { CLAIM/OVERALL } \\
\text { APPRECIATION of TARGET } \\
\text { (FRACKING) }\end{array}$ \\
\hline Meeting climate targets & Yes (disputable) & No & \multicolumn{1}{|l}{} \\
\hline
\end{tabular}




\begin{tabular}{|l|l|l|}
\hline Clean and safe energy & Yes (uncontroversial) & No \\
\hline Energy saving & Yes (uncontroversial) & No \\
\hline Economic productivity & Yes (uncontroversial) & Unlikely \\
\hline Meeting gas demand & Yes (disputable) & No \\
\hline $\begin{array}{l}\text { Environmental risks } \\
\text { (water contamination and } \\
\text { shortage and air } \\
\text { pollution) }\end{array}$ & No (uncontroversial) & Yes \\
\hline
\end{tabular}

The assumed fundamental evaluative premise for the negative APPRECIATION expressed in

Viewpoint 3 is, therefore, social VALUATION of compliance, energy saving, safety, environmental integrity, meeting gas demand and economic benefit.

\section{Viewpoint 4}

\section{Kevin Anderson, Deputy Director of the Tyndall Centre for Climate Change Research}

1 Shale gas is the same as natural gas - it is a high-carbon fuel, with around $75 \%$ of its mass made of carbon.

2 For the UK and other wealthy nations, shale gas cannot be a transition fuel to a low-carbon future. Anyone

3 who says differently does not understand our explicit international commitments under the Copenhagen

4 Accord, the Cancun Agreements - or, alternatively, is bad at maths.

5 The UK's commitment to make our fair contribution to reduce emissions in line with keeping global 6 warming below a $2 \mathrm{C}$ rise gives a very clear global carbon budget, and hence a UK budget: in other words, 7 how much carbon we can put into the atmosphere over this century. Here the maths is unambiguous - we 8 have insufficient budget for the carbon we are already emitting and by the time shale gas is produced in 9 any quantity (five to 10 years), there will be no emissions space left for it. The maths is that simple, even if 10 the conclusion is not what we want to hear.

11 Another fundamental mistake made by many experts on shale gas is that they assume it is lower-carbon 12 than coal, but this is valid only if we don't burn the coal. In a world that is hungry for energy, any UK shale 13 gas used here will mean we import less gas and coal - gas and coal that will simply be burnt elsewhere.

14 The climate does not care from which country the carbon comes from - so burn shale gas here and UK 15 emissions may go down but global emissions will go up. Shale gas is another high-carbon fossil fuel - it 16 just adds to the problem - in the absence of a stringent limit on total carbon emissions it will not substitute 17 for coal.

18 Finally, even if the technology of "carbon capture and storage" can be made to work with gas - the level of 19 emissions reductions will not be enough to meet our international carbon commitments. In the UK and 20 globally, we are now reaping the reward of a decade of hypocrisy and self-delusion on climate change. We 21 pretend we are doing something ourselves, whilst blaming others for rising emissions.

22 The truth is out - it is a tragedy of the commons par excellence - we are all to blame and we have left it too 23 late for a technical fix. We are heading towards a global temperature rise of $4 \mathrm{C}$ to $6 \mathrm{C}$ this century; if we 24 want to get off this trajectory, shale gas needs to stay in the ground and we, in the wealthy world, need to 25 consume much less energy - now. 
In Viewpoint 4, the overall negative APPRECIATION of fracking is expressed at its most explicit through the negative evaluation of shale gas, as the target product of fracking. The negative evaluation of shale gas is evoked ideationally in "it just adds to the problem" (L15-16) and "shale gas needs to stay in the ground" (L23). Further invocation is present through the negative JUDGMENT of experts who favour shale gas, whether they are referred to in general ("anyone who says differently does not understand...or is bad at math" in L2-4) or more specifically ("another fundamental mistake made by many experts" in L11). Further negative judgment, invoking negative APPRECIATION is also expressed of "us" as "hypocrite" (L20-21) and "to blame for the rise in the global temperature" (L 2225). Negative APPRECIATION is additionally invoked through expressions of negative AFFECT attributed to the climate ("the climate does not care...", L14) and the writer's qualification of the situation as "a tragedy of the commons par excellence" (L22).

If we start from the overall negative claim/ APPRECIATION of fracking conveyed by the piece, we can identify the primary underlying evaluative criterion as meeting climate targets (L3, 5, 9, 19). This is assumed to be desirable and presented as not applicable (L2-4; 6-10 and 19), should more shale gas be produced as a result of fracking. A further related criterion is the reduction of global gas/coal consumption (L12-17). This is also assumed to be desirable and presented as non-applicable, should more shale gas be produced (L11-17). Finally, an aspect of coal consumption, temperature rise, is included as a further related evaluative criterion (L23), which pertains to environmental integrity. Temperature rise is assumed to be undesirable and applicable, should more shale gas be produced (L23). As in the previous analyses, disputable and uncontroversial assumptions can be distinguished. The claim-premises analysis is summarised in Table 6.

Overall, therefore, the assumed fundamental evaluative premise of the negative APPRECIATION expressed in Viewpoint 4, is social VALUATION of compliance, environmental integrity and reduction in consumption, whilst VALUATION of safety and economic benefit is not implicated.

Table 6. Summary of Viewpoint 4 (Kevin Anderson - Tyndall Centre for Climate Change Research) 


\begin{tabular}{|c|c|c|c|}
\hline $\begin{array}{l}\text { EVALUATIVE } \\
\text { CRITERIA }\end{array}$ & $\begin{array}{l}\text { EVALUATION of } \\
\text { CRITERIA } \\
\text { (desirability) }\end{array}$ & Does it apply? & $\begin{array}{l}\text { CLAIM/OVERALL } \\
\text { APPRECIATION of } \\
\text { TARGET (FRACKING) }\end{array}$ \\
\hline Meeting climate targets & Yes (disputable) & No & \multirow{3}{*}{ } \\
\hline $\begin{array}{l}\text { Reduction in global coal } \\
\text { consumption }\end{array}$ & Yes (uncontroversial) & No & \\
\hline $\begin{array}{l}\text { Environmental risk } \\
\text { (temperature rise) }\end{array}$ & No (uncontroversial) & Yes & \\
\hline
\end{tabular}

\subsection{Summary of analysis and findings}

One can see that the viewpoints expressed in the BBC news article are mostly polarised, whereby each stakeholder presents either a completely positive or a completely negative view of fracking in relation to their selected evaluative criteria. The only exception is the Director of the Durham Energy Institute' view, in which the verdict is made dependent on our ability to control contamination.

The analysis shows that the negative or positive nature of the evaluation may be explored by observing how it is more or less implicitly conveyed through a number of expressive choices, including Appraisal categories of AFFECT and JUDGMENT as well as APPRECIATION. However, this level of analysis does not capture the full extent of the evaluation expressed in each text. By reversing the direction of the analysis in correspondence with the argumentative structure of the discourse and focusing more specifically on the presupposed evaluative premises on which the claims are based, it is possible to obtain a more comprehensive insight into the nature of the APPRECIATION expressed in each viewpoint. The analysis shows that the positive or negative APPRECIATION of fracking results, essentially, from the fact that the stakeholders base their evaluation on different evaluative premises at three main levels:

The assumptions relate firstly to what the opinion holders assume the value of fracking should be assessed on. There is a great deal of overlap across these criteria but one can see that there seems to be overall agreement on the value of environmental integrity, even though different aspects of this integrity are foregrounded in the different Viewpoints: water purity and avoidance of earthquakes in $\mathrm{V} 1$, reducing $\mathrm{CO} 2$ emissions and general environmental risk in $\mathrm{V} 2$, water purity and availability and air purity in V3 also and temperature rise in V4. Safety is also included as a criterion in three of the Viewpoints (V1, V2 and V3), where it is linked to the avoidance of environmental risks. In V2, safety 
is also mentioned as a separate value and with reference to health risks whilst, in V3, it is more specifically linked to energy. V1, V2 and V3 all refer to meeting gas demand, although V3 is, at the same time, questioning the validity of this premise (L16). V4 strongly undermines this premise. Economic benefit is used as a criterion in V1 and V3 only, whilst meeting climate targets is the most foregrounded criterion in V4 but also applies to V3. Energy saving is a criterion both in V3 and V4: more generally, in V3 and with more specific reference to global coal consumption, in V4. This level of comparison draws attention not only to the fact that different evaluative criteria are set up by different stakeholders but also to the fact that some aspects are not set up at all, e.g. aesthetics values (how fracking may affect the appearance of the landscape, for example) and further environmental aspects (effects on wildlife and animal species other than humans, for example). Therefore, whilst the premises are factual in themselves, the evaluative factor lies in the opinion holders' selection of the applicable premises.

The second level of analysis pertains to the assumptions as to whether the posited criteria are desirable or not. The analysis shows that, when considered, environmental integrity (albeit different aspects), safety, economic benefit, jobs, meeting climate targets, energy saving and meeting gas demand are assumed to be desirable and, conversely, lack of these conditions is not. However, whereas environmental integrity, safety and economic benefit and energy saving are, uncontroversially, desirable, the desirability of meeting climate targets, and meeting gas demand is disputable (as discussed in section 4.1 above). At this level of analysis, therefore, the disputability value of the assumptions adds to the overall evaluative basis of the claims.

Finally, the third level of analysis concerns the opinion holders' assumptions as to whether the desirable or non-desirable criteria would apply or not, should fracking be introduced. Regarding the aspects of environmental risks brought to bear on the argumentation, V1 (water contamination, earthquakes) and V2 (increase in CO2 emissions) assert that they would not apply, whilst V3 (water contamination and shortage and air pollution) and V4 (temperature rise) assert that they would apply. With regard to safety, it would apply in V1 and V2 but not in V3. Economic benefit is asserted to apply in V2 but not in V3. Meeting climate targets and reduction in energy consumption are presented as not applicable, when mentioned (in V3 and V4). Meeting gas demand is asserted to apply 
in V1 and V2 but not in V3 (where it is questioned as a valid criterion in the first place). Thus, the opinion holders' subjective positioning towards the applicability of their selected (un)desirable criteria, contributes the final evaluative component to the premises.

\section{Discussion}

In this section, the findings are discussed firstly with reference to their theoretical implications, specifically in the domains of evaluation, presupposition and argumentation (section 5.1) and, secondly, with respect to implications for environmental or other deliberations.

\subsection{Theoretical implications and further research}

The analysis illustrated in this paper extends our understanding of the pragmatics of evaluation with particular reference to the relationship between evaluation and discourse/text function. As mentioned in section 3, this relationship has been recently examined in detail in the book Evaluation in context, edited by Thompson \& Alba-Juez (2014). This work illustrates the value of exploring evaluative meaning from a pragmatic perspective and in the context of specific registers.

Like Labov \& Waletzky (1967), in their original study of evaluation in narrative registers, I firstly focused on the evaluative meaning of the text at a core level. In Labov \& Waletzky's analysis of narratives, this core level could be equated with the moral of a story or its main significance, as appreciated by the reader on completing the reading. In the case of the argumentative texts considered in the present paper, the core level is the main evaluative claim expressed in each viewpoint.

As pointed out by Macken-Horarik \& Isaac (2014: 81) with reference to narrative texts, "we need complementary ways of representing the prosodies and the dynamism of evaluative choices $[\ldots]$ alongside the synoptic but overly static displays of system networks". ${ }^{11}$ In the analysis presented in this paper, I have tried to show that the "synoptic displays of system networks" (the main claims in the viewpoints on fracking) are amenable to a similar dynamic analysis as the discreet or prosodic evaluative choices considered in most other work.

Ultimately, this paper provides further understanding of the evaluative basis of pragmatic presuppositions, extending existing research by Colomina-Almiñana (2018). The latter conceptualizes 
of pragmatic presuppositions as linking "attitudes" to "shared common ground", suggesting that presuppositions rely on "agreement in attitudes towards common ground" (Colomina-Almiñana 2018: 118). The analysis presented in this paper highlights in further detail the relationship between attitudes and common ground. Firstly, it shows that part of what counts as common ground depends on attitudes in the first place (the opinion holder's selection of the relevant evaluative premises). Secondly, it demonstrates that shared common ground may be more or less controversial, with semifactual, uncontroversial assumptions, on the one hand, and disputable, more clearly attitudinal assumptions, on the other. Thirdly, it points to the attitudinal component associated with assessing the applicability of the (un)desirable criteria.

With reference to argumentative theory, the findings are a reminder of the fact that, as in language in general, so in argumentation, the distinction between objective and subjective elements is not a sharp one. Ultimately, all claims can be seen to have an evaluative basis ${ }^{12}$ at some level, even though this may be more obvious in some registers (e.g. reviews) than others (e.g. scientific papers). To this extent, the findings are consistent with the informal logical and rhetorical approaches to argumentation mentioned in section 3 (see clarification in note 6).

Considering argumentation through the lens of evaluation, raises further interesting questions as to the nature of premises. This pertains to the ongoing debate, in argumentation theory, as to whether premises may be unexpressed or missing (e.g. Gerritsen 2001). As illustrated in the analysis, the identified evaluative premises are typically not expressed but assumed.

Further analysis, comparing the approach taken in this paper with a more traditional argumentative analysis of the texts, would be needed in order to gain a deeper understanding of the theoretical implications of the findings for argumentation theory.

As in most qualitative studies of evaluation in discourse, subjectivity of interpretation and interrater variability may undermine the validity of the findings, and measures need to be taken to ensure an acceptable level of transparency and replicability. Different readers may, for example, identify different central claims in argumentative texts, particularly if they are more complex than the ones examined in this paper. Readers/analysts' interpretation may also vary depending on the different knowledge of the topic that is being argued for or against. Through the process of searching 
for the underlying premises of the claims, it is, however, possible, at least to some extent, to test the validity of the initial interpretations and to adjust them accordingly, as the analysis proceeds.

Whilst, in this paper, the dimensions of presupposed evaluation were explored with reference to APPRECIATION in a particular type of argumentative discourse, further analysis may be undertaken to investigate whether this approach may be applied to other forms of evaluation (i.e. AFFECT and JUDGEMENT) in argumentative, persuasive or narrative discourse, ranging from advertising to political debates and stories for children.

\subsection{Environmental deliberation}

Ecological economists (e.g. Wilson \& Howarth 2002: 436) argue that environmental debates using a consensus-based deliberative style, in which stakeholders are encouraged to consider and express the values that underlie their different positions, would reduce unhelpful view polarization and facilitate reasoned and more effective policy negotiation. The case study presented in this paper supports this position insofar as it exposes the deeper-seated evaluative premises on which environmental claims are made in everyday discourse.

The analysis shows how evaluative meaning is conveyed through layers of overlapping assumptions spread throughout each Viewpoint and how this may be captured by tracing each layer systematically. In the context of wider and long-lasting deliberations, leading to the development of environmental decisions and policies, a similar process may be used to highlight and probe this kind of elusive evaluative criteria and assumptions. In these cases, however, the analysis is likely to prove more challenging in that authentic deliberations would typically include a wider variety of views and, perhaps, less polarised and more complex positions than in the example of media coverage considered in this paper. We have seen, for example, that all opinion holders, in the Viewpoints examined, build their claims on VALUATION i.e. the worth ascribed to the socio-cultural criteria that they have selected. According to these criteria, fracking is represented as (un)safe, environmentally (un)friendly or economically beneficial/detrimental. In other contexts, however, the main claims may be grounded in other forms of APPRECIATION i.e. aesthetic or emotive REACTION (see section 4.1), resulting in fracking being represented, for example, as ugly, disgusting, innovative or exciting. 
Even though it would be unrealistic to think that all underlying evaluative premises may be uncovered and further debated in this way, it may be productive for the deliberating parties to become aware of some of the premises on which their claims are based. This may be particularly useful when debating measures for the protection of particular environmental assets, such as a green areas or biodiversity. While all stakeholders may agree that protection is desirable, they may disagree on how this may be achieved, depending on what exactly they value about green areas or biodiversity. Those who wish to protect a forest for the value of the plant species it supports, for example, would leave the forest as close as possible to its original state, while those who value forests as places for people to walk through and enjoy the beauty of trees and birds, may be happy for paths and bird hides to be introduced, even though this may detrimentally affect some of the native plant species. It is precisely these often assumed rather than directly acknowledged values that the analysis presented above has drawn attention to. Opinion holders who wish and are able to respond to the increased awareness that this exploration may bring, would arguably find it easier to identify collective social priorities and reach a wider consensus on the required policies.

Ultimately, increased awareness of the 'hidden' values on the basis of which environmental decisions are made, would strengthen the consultative processes, leading to more successful environmental management, which, as stated by Davies (2006: 102), requires that we attempt to "better understand people's visions of nature in place", involving "a variety of philosophical conceptions of nature-society interactions".

\section{Conclusive remarks}

This paper makes an original contribution to the theoretical understanding of evaluative discourse and its pragmatic dimensions, whilst, at the same time, highlighting the evaluative roots of pragmatic presuppositions and argumentation.

By specifically exploring the evaluative premises on which views on the practice of fracking are based, the analysis also has practical implications for current thinking in environmental policy, adding a new perspective to the ongoing debate on environmental (e)-valuation and, particularly, the 
notion that current deliberations do not necessarily promote the exploration of all values at stake (as argued, for example, by Vargas et al. 2017).

\section{References}

BBC News 5 January 2013 Viewpoints: fracking's risks and benefits http://www.bbc.co.uk/news/science-environment-20758673NT

Bednarek, Monika. 2006. Evaluation in media discourse: Analysis of a newspaper corpus. New York, London: Continuum.

Bednarek, Monika. 2008. Emotion talk across corpora. Basingstoke and New York: Palgrave MacMillan.

Benamara, Farah, Maite, Taboada \& Yannick, Mathieu. 2017. Evaluative language beyond bags of words: Linguistic insights and computational applications. Computational Linguisitcs 43(1). 201-264.

Colomina-Almiñana, Juan, J. 2018. Pragmatic presuppositions and articulated constituents. Lingua 206. $112-126$.

Davies, Anna, R. 2006. Nature in place: Public visions of nature-society relationships in the UK. In Riyan, J.G. Van den Born, Rob, H.J. Lenders \& Wouter, T. de Groot (eds.), Visions of nature, 85-106. Berlin: Lit Verlag.

Eemeren, Frans. H. van \& Rob, Grootendorst. 2003. A systematic theory of argumentation. The Pragma-Dialectical approach. Cambridge: Cambridge University Press.

Gerritsen, Susanne. 2001. Unexpressed premises. In Frans, H. van Eemeren (ed.), Crucial concepts in argumentation theory, 51-79. Amsterdam: Amsterdam University Press.

Johnson, Ralph H. \& Blair, J. Anthony. 2006. Logical self-defence. New York: International Debate Education Association.

Halliday, Michael, A.K. \& Christian, Matthiesen, 2004. An introduction to Functional Grammar, 
3rd edn. London: Edward Arnold.

Hommerberg, Charlotte. 2015. Bringing consumption reviews into relief by combining Appraisal and argumentation analysis. Text and Talk 35(2): 155-175.

Hommerberg, Charlotte \& Alexanne, Don. 2015. Appraisal and the language of wine appreciation: a critical discussion of the potential of the appraisal framework as a tool to analyse specialised genres. Functions of Language 22(2). 161-191.

Hood, Susan \& Martin, James. 2007. Invoking attitude: The play of graduation in appraising discourse. In Ruqaiya, Hasan, Christian M.I.M., Matthiessen \& Jonathan, Webster (eds), Continuing discourse on language: A functional perspective vol. 2, 739-764. London: Equinox.

Hunston, Susan. 1989. Evaluation in experimental research articles. Unpublished $\mathrm{PhD}$ thesis, University of Birmingham.

Hunston, Susan \& Geoff, Thompson (eds.) 1999. Evaluation in text. Authorial stance and the construction of discourse. Oxford: Oxford University Press.

Hyland, Ken. 2002. What do they mean? Questions in academic writing. Text 22(4). 259-557.

Labov, William \& Joshua, Valetzky. 1967. Narrative analysis. In June, Helm (ed), Essays on the verbal and visual arts, 12-44. Seattle: University of Washington Press.

Lemke, Jay. 1998. Resources for attitudinal meaning: Evaluative orientations in text semantics. Functions of Language 5(1). 33-56. doi:10.1075/fol.5.1.031em

Kaltenbacher, Martin. 2006. Culture related linguistic differences in tourist websites: the emotive and the factual. A corpus analysis within the framework of appraisal. In Geoff, Thompson \& Susan, Hunston (eds), System and corpus. Exploring connections, 269-292. London: Equinox.

Macken-Horarik, Mary \& Anne, Isaac. 2014. Appraising appraisal. In Geoff Thompson \& Laura Alba-Juez (eds), Evaluation in context, 67-92. Amsterdam: John Benjamins.

Martin, James, R. \& Peter, R. R. White. 2005. The language of evaluation. Appraisal in English. Basingstoke: Palgrave Macmillan.

Pounds, Gabrina. 2005. Writer's argumentative attitude: A contrastive analysis of Letters to the Editor 
in English and Italian. Pragmatics 15(1). 49-88.

Pounds, Gabrina. 2011. "This property offers much character and charm": Evaluation in the discourse of online property advertising. Text and Talk 31(2). 195-220.

Thompson, Geoff \& Laura, Alba-Juez, (eds). 2014. Evaluation in context. Amsterdam: Benjamins.

Toulmin, Stephen E., Richard, Rieke \& Allan, S. Janik. 1979. An introduction to reasoning. New York: Macmillan.

Toulmin, Stephen E. 2003. The uses of argument. Cambridge: Cambridge University Press.

Vargas, Andrès, Michael, Howes \& Nicholas, Rohde. 2017. The problem of inclusion in deliberative environmental evaluation. Environmental values 26. 157-176.

Walton, Douglas. 2009. Argumentation theory: a very short introduction. In Guillermo, Simari \& Iyad, Rahwan (eds), Argumentation in artificial intelligence, 1-22. Berlin: Springer.

White, Peter, R. R. 2006. Evaluative semantics and ideological positioning in journalistic discourse. A new framework for analysis. In Inger, Lassen, Jeanne, Strunck \& Torben, Vestergaard (eds), Mediating ideology in text and image, 37-67. Amsterdam: Benjamins.

Wilson, Matthew. A. \& Richard, B. Howarth. 2002. Discourse-based valuation of ecosystem services: Establishing fair outcomes through group deliberation. Ecological Economics 1. 431-443.

Wu, Siew Mei \& Allison, Desmond. 2005. Evaluative expressions in analytical arguments: Aspects of appraisal in assigned English language essays. Journal of Applied Linguistics 2(1). 105-27.

\footnotetext{
${ }^{1}$ The practice is controversial because of its potential environmental risks and negative impact.

${ }^{2}$ Notice that the term 'evaluative premise' is not used in argumentation theory. Premises are typically understood as propositions that provide evidence or justification for a claim or conclusion. The new term, 'evaluative premise', is introduced in this paper to highlight the evaluative basis of the claims, as illustrated in the analysis.

${ }^{3}$ It must be noted, however, that Martin and White (2005) see feelings as central to evaluation, pertaining not only to explicit affectual expression (AFFECT) but also to JUDGMENT and APPRECIATION, which are understood as forms of institutionalized feelings

${ }_{5}^{4}$ My examples

5 'Normative standards', in argumentation theory, refer to the criteria by which the validity or reasonability of arguments may be assessed.

${ }^{6}$ The latter views are known as 'informal logical' and 'rhetorical' approaches.

${ }^{7}$ See further discussion of this global reading position in section 5.2 below with reference to Macken-Horarik and Isaac's observations, 2014:81.

${ }^{8}$ This is an example of the journalistic tendency towards dramatization of the stories to make them more exciting and sensational (Bednarek 2008).

${ }^{9}$ Both in selecting these particular viewpoints and in ordering them in a particular way.
} 
${ }^{10}$ I am not excluding that JUDGEMENT (of people) may be included in environmental deliberations since positive or negative stances may be expressed of institutions and individuals who can be seen to support negative or positive practice.

${ }^{11}$ My italics

${ }^{12}$ Or 'normative' basis (see Note 5). 